\title{
Effect of Botulinum Toxin A Injection into the Salivary Glands for Sialorrhea in Children with Neurologic Disorders
}

\author{
In Seuk Jeung, M.D., Soyoung Lee, M.D., Heung Sik Kim, M.D. ${ }^{1}$, Chang Ki Yeo, M.D. ${ }^{2}$ \\ Departments of Rehabilitation Medicine, ${ }^{1}$ Pediatrics, ${ }^{2}$ Otolaryngology, Dongsan Medical Center, \\ Keimyung University School of Medicine, Daegu 700-712, Korea
}

\begin{abstract}
Objective To determine the 9 month period effect of botulinum toxin A (BoNT-A) injection into the salivary gland in children with neurologic disorders and sialorrhea by qualified parent/caregiver-administered questionnaires.

Method A total of 17 patients (age 7.6 \pm 4.24 years) were enrolled in this study. The degree of sialorrhea was assessed at the baseline, 2 weeks, 1, 2, 4, 6 and 9 months after injection. The Drooling Count (DC) was assessed as an objective measurement. The Drooling Frequency and Severity Scale (DFS) and the Teacher Drooling Scale (TDS) were evaluated as a subjective measurement. BoNT-A ( $0.5 \mathrm{unit} / \mathrm{kg})$ was injected into each submandibular and parotid gland under ultrasonography-guidance.

Results DC, DFS and TDS showed significant improvement at 2 weeks, 1, 2, 4, 6, and 9 months follow-up ( $<<0.05$ ). Twelve of 17 cases $(70.5 \%)$ showed more than $50 \%$ reduction in DC from the baseline value.

Conclusion Ultrasonography-guided BoNT-A injection into the submandibular and parotid gland was a safe and effective method to treat sialorrhea in children with neurologic disorders.
\end{abstract}

Key Words Sialorrhea, Botulinum toxin, Salivary gland, Children, Neurologic disorder

\section{INTRODUCTION}

Sialorrhea is a common and severe problem in children and adults with cerebral palsy or neurologic disorders. Sialorrhea creates major hygienic and psychosocial

\section{Received December 7, 2011; Accepted April 19, 2012}

Corresponding author: Soyoung Lee

Department of Rehabilitation Medicine, Dongsan Medical Center, Keimyung University School of Medicine, 56 Dalseong-ro, Jung-gu, Daegu 700-712, Korea

Tel: +82-53-250-7264, Fax: +82-53-250-7268, E-mail: sylee@dsmc.or.kr (c) This is an open-access article distributed under the terms of the Creative Commons Attribution Non-Commercial License (http:// creativecommons.org/licenses/by-nc/3.0) which permits unrestricted noncommercial use, distribution, and reproduction in any medium, provided the original work is properly cited.

Copyright ( 2012 by Korean Academy of Rehabilitation Medicine problems. Sialorrhea can create major hygienic and psychological issues and families and children become subjected to extreme stress and social isolation. Due to sialorrhea, affected children may have skin maceration around the mouth, perioral dermatitis, or even dehydration. ${ }^{1}$ Many methods have been used to treat sialorrhea, including oral motor therapy, intraoral devices, medication, and surgery. However, oral motor therapy and intraoral devices are not suitable for children with severe disability because the effects are short and require continuous therapy. Anticholinergic medications are often poorly tolerated due to a high prevalence of side effects including constipation, urinary retention, orthostatic hypotension, bradycardia, irritability and drowsiness. 
Surgery is an invasive procedure that is often unacceptable by parents and had some complications including increased dental caries, gingival problems, parotitis, and postoperative cysts and fistulae. ${ }^{2}$ The secretion of saliva is under parasympathetic autonomic control with acetylcholine working as the specific neurotransmitter. Down regulation of acetylcholine would theoretically lead to a reduction in the production of saliva. BoNT-A has shown to exert an effect at the neuroglandular junction in animal study by causing reversible reduction in acetylcholine release from presynaptic nerve terminal. ${ }^{3}$

Recently botulinum toxin A (BoNT-A) injections have been used to treat sialorrhea in adults with Parkinson's disease, head and neck cancer, stroke, and neurodegenerative disease. Several studies have reported that BoNT-A injections into the salivary gland are effective for sialorrhea in children with cerebral palsy or other neurological disease without any severe side effects. ${ }^{1,4-6}$ Marked differences have been observed for the effective dose of BoNT-A and the injection site. There is no consensus or guidelines about BoNT-A dosage or which salivary glands should be injected.

The purpose of this study was to evaluate the effect of a BoNT-A injection into the salivary glands to treat sialorrhea in children with neurologic disorders during 9 months.

\section{MATERIALS AND METHODS}

\section{Subjects}

Children with cerebral palsy or other neurologic disorders were included in this study between January 2010 and November 2010, whose Drooling Frequency and Severity Scale scores were $>4$ and who were suffering from sialorrhea. The exclusion criteria were: (1) general contraindications for a BoNT-A injection such as myasthenia gravis and Lambert-Eaton syndrome (2) received a BoNT-A injection in the previous 3 months, (3) administered systemic drug therapies to treat sialorrhea in the previous 3 months, and (4) previous maxillofacial surgery that might interfere with salivary production or flow. Possible adverse effects and risks related to the interventions were explained to the parents or caregivers, and written informed consent was obtained. Seventeen patients (nine boys and eight girls) were included. The mean age of the patients was $7.6 \pm 4.24$ years, and the diagnosis was cerebral palsy in 15, Down syndrome in 1, and mental retardation in 1 . Three patients were fed via a nasogastric tube, the remaining 14 patients were fed orally. Children with cerebral palsy, lack independence even in basic postural control and all areas of motor function are limited (Gross Motor Function Classification System, GMFCS Level V). A child with Down syndrome would be unable to maintain head and trunk against gravity in a prone and sitting position. A child with mental retardation would be unable to walk without assistance. Participant characteristics are shown in Table 1. This protocol was approved by the institutional review board.

\section{Methods}

Two $\mathrm{ml}$ of normal saline was used to dilute 100 units of BoNT-A (Botox ${ }^{\circledR}$, Allergan Inc., Mayo, Ireland). Each parotid and submandibular gland had injected with 0.5 units of BoNT-A $/ \mathrm{kg}$ body weight. A 25 -guage $3.8 \mathrm{~cm}$ needle was used to inject each site. One child, who had posterior drooling only during sleep, received bilateral submandibular glands injections. In total of 15-80 units of BoNT-A were injected into bilateral salivary glands. Patients were placed in a supine position where the head could be rotated to each side. The parotid glands lie superficially but the submandibular gland is difficult to accurately locate by palpation. We injected BoNT-A into the salivary glands under ultrasonography-guidance without

Table 1. General Characteristics of Subjects

\begin{tabular}{|c|c|c|}
\hline \multicolumn{3}{|c|}{ Characteristics $(\mathrm{N}=17)$} \\
\hline \multirow[t]{2}{*}{ Sex } & Male & 9 \\
\hline & Female & 8 \\
\hline Age (years & & $7.6 \pm 4.24$ \\
\hline \multicolumn{2}{|c|}{ Body weight $(\mathrm{kg})$} & $15.7 \pm 7.01$ \\
\hline \multirow[t]{6}{*}{ Diagnosis } & Cerebral palsy & 15 \\
\hline & Spastic diplegia & 3 \\
\hline & Spastic quadriplegia & 11 \\
\hline & Dyskinetic & 1 \\
\hline & Down syndrome & 1 \\
\hline & Mental retardation & 1 \\
\hline \multirow[t]{2}{*}{ Feeding } & Oral & 14 \\
\hline & Nonoral & 3 \\
\hline \multicolumn{2}{|c|}{ On drooling medication before study } & 0 \\
\hline \multicolumn{2}{|c|}{ Previous history of aspiration pneumonia } & 2 \\
\hline
\end{tabular}

Values of age and body weight are mean \pm standard deviation 
anesthesia. Ultrasonography ACCUVIX V10 ${ }^{\circledR}$ (Medison Co., Seoul, Korea) demonstrated the exact location, depth and vascular supply of the salivary glands.

After receiving specific instructions, parents filled out a parent/caregiver-administered questionnaire. Parents were asked to rate their children's drooling before and after the injections using the Drooling Count, the Drooling Frequency and Severity Scale and the Teacher Drooling Scale $^{7}$ (Appendices 1, 2). The Drooling Count was measured in the morning at least 1 hour after a meal, while each child was awake and sitting upright. The absence or presence of new saliva on the lip was recorded for 10 minutes. Parents were asked to register all possible side effects in a diary. Outcome measurements were assessed before an injection, at 2 weeks, 1, 2, 4, 6, and 9 months after an injection. The Drooling Count, an objective method, served as the primary outcome measure and the Drooling Frequency and Severity Scale and the Teacher Drooling Scale, subjective methods, served as secondary outcome measures. The treatment response was rated as successful when there was more than $50 \%$ reduction in
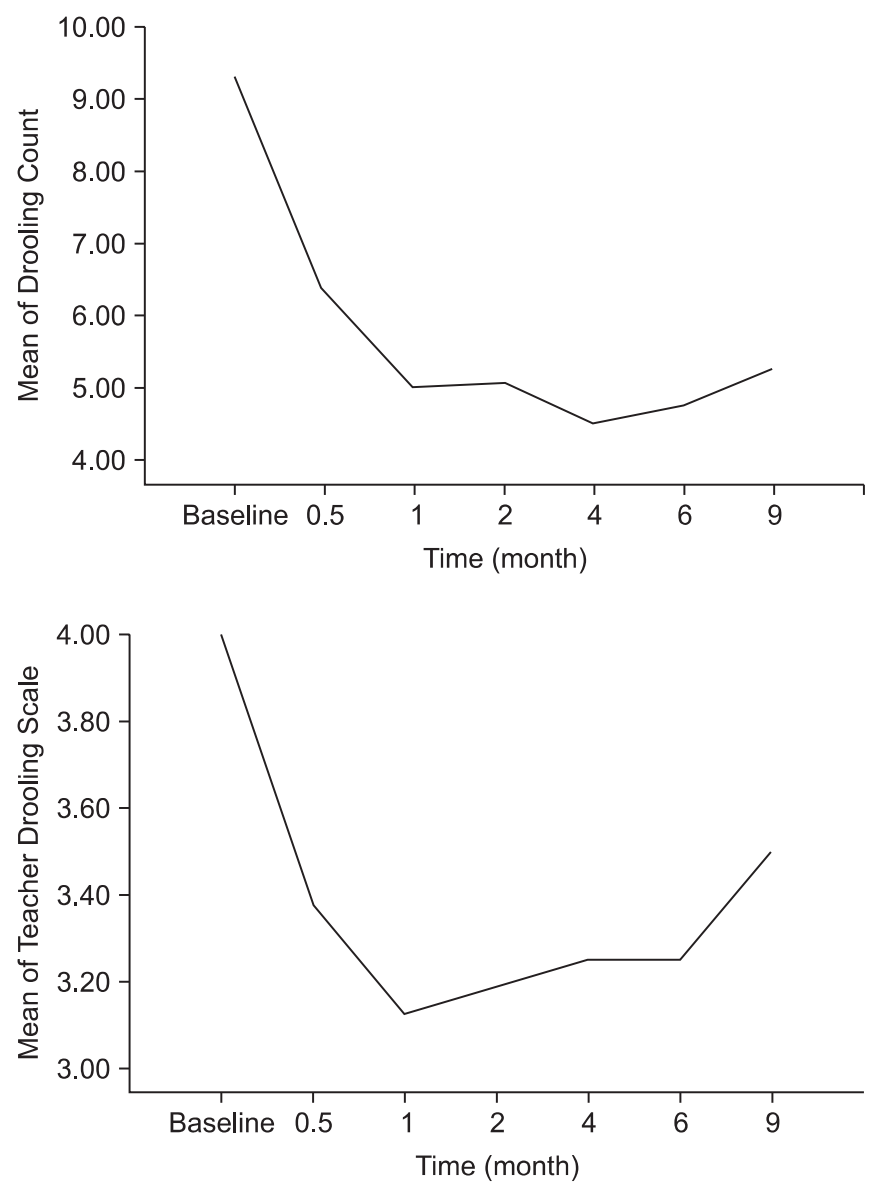

the Drooling Count than the baseline value. We defined more than 2-point decrease as successful in the Teacher Drooling Scale.

Table 2. Mean Differences between Baseline and Followup Measurements

\begin{tabular}{cccc}
\hline $\begin{array}{c}\text { Pairs of } \\
\text { observation }\end{array}$ & $\begin{array}{c}\text { DC } \\
\text { difference }\end{array}$ & $\begin{array}{c}\text { DFS } \\
\text { difference }\end{array}$ & $\begin{array}{c}\text { TDS } \\
\text { difference }\end{array}$ \\
\hline BL/BoNT 2 wk & $3.17(5.91)^{*}$ & $0.76(1.20)^{*}$ & $0.58(0.87)^{*}$ \\
\hline BL/BoNT 1 mo & $4.35(4.54)^{*}$ & $1.00(1.50)^{*}$ & $0.82(1.07)^{*}$ \\
\hline BL/BoNT 2 mo & $4.00(6.64)^{*}$ & $1.00(1.62)^{*}$ & $0.76(0.97)^{*}$ \\
\hline BL/BoNT 4 mo & $4.82(6.20)^{*}$ & $1.05(1.63)^{*}$ & $0.70(0.84)^{*}$ \\
\hline BL/BoNT 6 mo & $4.88(7.23)^{*}$ & $1.11(1.45)^{*}$ & $0.76(0.90)^{*}$ \\
\hline BL/BoNT 9 mo & $4.06(1.57)^{*}$ & $1.00(1.59)^{*}$ & $0.50(0.89)^{*}$ \\
\hline
\end{tabular}

Values are mean (standard deviation)

BL: Baseline scores before botulinum toxin A injection, DC: Drool count, DFS: Drooling Frequency and Severity Scale, TDS: Teacher Drooling Scale ${ }^{*} \mathrm{p}<0.05,{ }^{\dagger}$ The last result of the patient who had received percutaneous endoscopic gastrostomy was excluded at 9 months

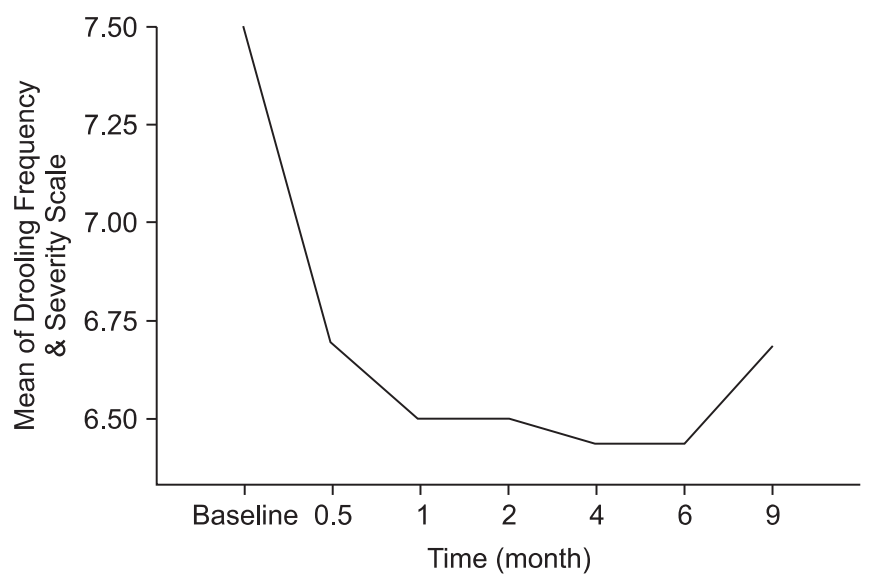

Fig. 1. Changes of the mean scores of drooling measurements for 9 months $(n=6$, one patient was excluded due to a percutaneous endoscopic gastrostomy). 


\section{Statistical analysis}

Statistical analysis was performed using SPSS software version 17.0 (SPSS $^{\circledR}$, Chicago, USA). We conducted the Wilcoxon signed-ranks test to assess differences in paired observations. A $\mathrm{p}<0.05$ was considered significant. Efficacy of the BoNT-A injection was rated when the treatment response was over 50\% reduction in the Drooling Count and more than 2-point decrease in the Teacher Drooling Scale than the baseline values.

\section{RESULTS}

The Drooling Frequency and Severity Scale, the Teacher Drooling Scale and the Drooling Count were evaluated for 9 months following the BoNT-A injections. One of the 17 patients underwent a percutaneous endoscopic gastrostomy and could not be evaluated at 9 months. The Drooling Frequency and Severity Scale, the Teacher Drooling Scale and the Drooling Count showed a significant decrease at 2 weeks, $1,2,4$, and 6 months after the BoNT-A injections $(\mathrm{p}<0.05)$ than the baseline values. At 9 months, 16 of 17 patients showed significant improvements in all measurements $(\mathrm{p}<0.05)$ (Table 2).

The mean scores of all measurements in 16 patients, except the patient that had withdrawn from the study) are shown in Fig. 1. The onset of therapeutic effect was within 2 weeks and showed marked improvement at the first month. The Drooling Count decreased up until 4 months. The Drooling Frequency and Severity Scale decreased for up to 6 months. The Teacher Drooling Scale showed marked decline at 1 month after the BoNT-A injections. The therapeutic effects were maintained significantly for 9 months in all measurements. No side effects were observed during the study.

Efficacy was observed in 12 of 17 cases (70.5\%) when the treatment response was rated as over $50 \%$ reduction in the Drooling Count than the baseline value. When we defined more than a 2-point decrease as successful in the Teacher Drooling Scale, efficacy was observed in 6 of 17 cases (35.2\%).

\section{DISCUSSION}

Botulinum toxin injections into the salivary glands have been proposed for treating sialorrhea in patients with amyotrophic lateral sclerosis or other neurologic disor- ders since $1997 .{ }^{8}$ BoNT-A, used as a spasticity treatment, weakens the muscles for 3-4 months. ${ }^{9}$ As in the salivary gland, the effect of the BoNT-A injection was reported to last for 6 months. ${ }^{6,10}$ In our study, overall therapeutic effects were persisted significantly for up to 9 months $(\mathrm{p}<0.05)$.

Salivary glands in healthy individuals secrete 1-1.5 L of saliva every 24 hours. The parotid and submandibular glands account for $90 \%$ of the secretion, the remaining $10 \%$ of secretion is produced by the sublingual and other minor glands. ${ }^{11}$ The submandibular glands produce 65 $70 \%$ of all saliva, and these glands continue to produce saliva when a person is not eating or drinking. The sublingual glands produce small amounts of thicker saliva that tends to coat the teeth. The parotid glands produce watery saliva, $20 \%$ of the total production, and the activity of this gland increases mainly during gustatory stimulation. ${ }^{2}$ There were different selections of the injected gland; the parotid gland, the submandibular gland, and both glands in the previous studies. ${ }^{1,4-6,10}$ The submandibular glands were chosen because this avoids reduced output of saliva while the patient eats and drinks. Since most children suffered from drooling with or without meals, we injected both glands. One child suffered from only posterior drooling during sleep, was injected into bilateral submandibular glands.

Ten-one hundred unit Botox ${ }^{\circledR}$ or 20-300 unit Dysport ${ }^{\circledR}$ (Speywood Pharmaceuticals Ltd., Maidenhead, UK) has been used to treat sialorrhea, but no conclusion has been reached regarding the ideal dose to obtain the best and longest therapeutic effect without side effects. ${ }^{10}$ In one study, 100 units of Botox ${ }^{\circledR}$ was injected into bilateral parotid and submandibular glands to reduce drooling in children with neurologic disorders and the effect lasted for 6 months. But, side effects were reported such as difficulties in swallowing and speech, pulmonary infection, and seizure..$^{12}$ In other studies, 1 unit/kg of Botox ${ }^{\circledR}$ was injected into each submandibular gland in children with cerebral palsy, and the effect lasted for 6 months. But side effects were reported such as dysphagia. ${ }^{6,13}$ Adverse side effects reported with the use of BoNT-A for sialorrhea were such as dysphagia, dry mouth, chewing difficulties, and recurrent mandibular luxation. ${ }^{14-16}$ Therefore, it is important to keep the doses low to avoid potential side effects due to spread of the toxin to surrounding tissues. A previously published study demonstrated no severe 
adverse effects with total 2 unit/kg of Botox ${ }^{\circledR}$ for 12-week follow-up. ${ }^{1}$ In that study, an injection of $0.7 \mathrm{unit} / \mathrm{kg}$ was given to each parotid gland and injection of 0.3 unit/ $\mathrm{kg}$ for each submandibular gland because the parotid glands are larger than the submandibular gland. We used a total 2 unit $/ \mathrm{kg}$ of Botox ${ }^{\circledR}$ and 0.5 unit $/ \mathrm{kg}$ of Botox $^{\circledR}$ in each parotid and submandibular gland injection equally. The patients showed statistically significant improvements without any side effects throughout the follow-up period for up to 9 months.

The parotid glands lie superficially and were injected blindly in the previous studies. ${ }^{8,11}$ Erroneous injections into the masseter muscle, Stensen's duct, facial nerve, or transverse facial artery can be avoided by using ultrasonography-guidance. The submandibular gland is difficult to locate accurately by palpation, because the gland is smaller than the parotid gland and situated on the inferiomedial aspect of the mandible. Thus, this gland should be injected under ultrasonography-guidance. ${ }^{17}$ Ultrasonography-guided injections have a better effect compared with blind injections, because they allows more accurate delivery of BoNT-A into the gland. ${ }^{16} \mathrm{We}$ injected under ultrasonography-guidance without general anesthesia that could be helpful to apply easily at the outpatient clinic.

Children with sialorrhea have been treated with BoNTA injections to the salivary glands under general anesthesia. In our study, children were given an injection under ultrasonography-guidance without sedation in an outpatient clinic. There were no injection-related or drug-induced side effects, which may have been related to ultrasonography-guidance.

The response rate to BoNT-A was $70.5 \%$ in the Drooling Count. However, in the Teacher Drooling Scale as a subjective measurement, the success rate was $35.2 \%$. One of the five children, who was not included as successful in the Drooling Count had only posterior drooling and showed clinical improvement in posterior drooling after the BoNT-A injection. The child also showed more than a 2-point decrease on the Teacher Drooling Scale and decrease on the Drooling Frequency and Severity Scale. The child's subjective measurement decreased whereas another child's measurement had no decreases, even within the subjective measurement. The reason for the lower success rate of the Teacher Drooling Scale was that the effect of the BoNT-A injections may have been per- ceived subjectively by parents, depending on their hopes and expectations about the treatment. Further research is needed in order to consider the factors by which this result may occur.

Children with spastic cerebral palsy received anticonvulsant or antispastic medications that might have had an affect on drooling. Three patients had increasing doses of antispastic medication, which may have produced a dry mouth. Two of them showed no improvements in the Drooling Scales and the Drooling Count. However, the other showed a decrease in the Drooling Count, which may have been related to the antispastic medication. Additionally, the Drooling Count may be affected by many factors such as the time of day, posture, and activity. Thus, each child should be assessed at the same time, in the same posture, and while performing a similar activity, which would increase the accuracy of study. Except for these three children, the response rate to BoNT-A was $78.5 \%$ when the effectiveness of treatment was defined as a $50 \%$ reduction in the Drooling Count from the baseline value.

Future studies should be conducted without changing medication doses that might affect drooling, such as anticonvulsants or antispastic drugs. The limitation of this study was that we could not exclude the effect of between-subject variations due to various responses to the parent-administered questionnaire. Inter-rator reliability could be increased by educating parents or caregivers who scored the subjective measurements. Furthermore, controlled studies are needed to assess the most effective and safest injection sites and doses.

\section{CONCLUSION}

This study was conducted to determine the clinical effect of ultrasonography-guided BoNT-A injections into the salivary glands to treat sialorrhea in children with neurologic disorders during 9 months. $70.5 \%$ of the children showed a successful reduction in the Drooling Count.

The Therapeutic effects were maintained significantly for 9 months in all measurements and no side effects were observed during the study.

Ultrasonography-guided BoNT-A injections into bilateral parotid and submandibular glands is a safe and effective treatment for sialorrhea in children with neuro- 
logic disorders.

\section{REFERENCES}

1. Banerjee KJ, Glasson C, O'Flaherty SJ. Parotid and submandibular botulinum toxin A injections for sialorrhoea in children with cerebral palsy. Dev Med Child Neurol 2006; 48: 883-887

2. Fairhurst $\mathrm{CB}$, Cockerill H. Management of drooling in children. Arch Dis Child Educ Pract Ed 2011; 96: 25-30

3. Ellies M, Laskawi R, Götz W, Arglebe C, Tormählen G. Immunohistochemical and morphometric investigations of the influence of botulinum toxin on the submandibular gland of the rat. Eur Arch Otorhinolaryngol 1999; 256: 148-152

4. Jongerius PH, Rotteveel JJ, van den Hoogen F, Joosten F, van Hulst K, Gabreels FJ. Botulinum toxin A: a new option for treatment of drooling in children with cerebral palsy. Presentation of a case series. Eur J Pediatr 2001; 160: 509-512

5. Bothwell JE, Clarke K, Dooley JM, Gordon KE, Anderson R, Wood EP, Camfield CS, Camfield PR. Botulinum toxin $\mathrm{A}$ as a treatment for excessive drooling in children. Pediatr Neurol 2002; 27: 18-22

6. Jongerius PH, van den Hoogen FJ, van Limbeek J, Gabreels FJ, van Hulst K, Rotteveel JJ. Effect of botulinum toxin in the treatment of drooling: a controlled clinical trial. Pediatrics 2004; 114: 620-627

7. Camp-Bruno JA, Winsberg BG, Green-Parsons AR, Abrams JP. Efficacy of benztropine therapy for drooling. Dev Med Child Neurol 1989; 31: 309-319

8. Bushara KO. Sialorrhea in amyotrophic lateral sclerosis: a hypothesis of a new treatment--botulinum toxin A injections of the parotid glands. Med Hypotheses 1997; 48: 337-339

9. Simpson DM. Clinical trials of botulinum toxin in the treatment of spasticity. Muscle Nerve Suppl 1997; 6: S169-175

10. Fuster Torres MA, Berini Aytes L, Gay Escoda C. Salivary gland application of botulinum toxin for the treatment of sialorrhea. Med Oral Patol Oral Cir Bucal 2007; 12: E511-517

11. Glickman S, Deaney CN. Treatment of relative sialorrhoea with botulinum toxin type A: description and rationale for an injection procedure with case report. Eur J Neurol 2001; 8: 567-571

12. Reid SM, Johnstone BR, Westbury C, Rawicki B, Reddihough DS. Randomized trial of botulinum toxin injections into the salivary glands to reduce drooling in children with neurological disorders. Dev Med Child Neurol 2008; 50: 123-128

13. Jongerius PH, Rotteveel JJ, van Limbeek J, Gabreels FJ, van Hulst K, van den Hoogen FJ. Botulinum toxin effect on salivary flow rate in children with cerebral palsy. Neurology 2004; 63: 1371-1375

14. Bhatia KP, Munchau A, Brown P. Botulinum toxin is a useful treatment in excessive drooling in saliva. J Neurol Neurosurg Psychiatry 1999; 67: 697

15. Tan EK, Lo YL, Seah A, Auchus AP. Recurrent jaw dislocation after botulinum toxin treatment for sialorrhoea in amyotrophic lateral sclerosis. J Neurol Sci 2001; 190: 95-97

16. Dogu O, Apaydin D, Sevim S, Talas DU, Aral M. Ultrasound-guided versus 'blind' intraparotid injections of botulinum toxin-A for the treatment of sialorrhoea in patients with Parkinson's disease. Clin Neurol Neurosurg 2004; 106: 93-96

17. Jongerius PH, Joosten F, Hoogen FJ, Gabreels FJ, Rotteveel JJ. The treatment of drooling by ultrasoundguided intraglandular injections of botulinum toxin type A into the salivary glands. Laryngoscope 2003; 113: 107-111 


\begin{tabular}{|cl}
\hline Appendix 1. Drooling Frequency and Severity Scale \\
\hline Frequency & \\
\hline 1 & Never \\
\hline 3 & Occasionally (not every day) \\
\hline 4 & Frequently (part of every day) \\
\hline Severity & Constantly \\
\hline 1 & Dry (never drools) \\
\hline 2 & Mild (only lips wet) \\
3 & Moderate (wet on lips and chin) \\
\hline 4 & Severe (drool extends to clothes wet) \\
\hline 5 & Profuse (hands, tray and objects wet) \\
\hline
\end{tabular}

\begin{tabular}{cl} 
Appendix 2. & Teacher Drooling Scale \\
\hline Teacher Drooling Scale \\
1 & No drooling \\
2 & Infrequent drooling; small amount \\
3 & Occasional drooling; intermittent all day \\
4 & Frequent drooling but not profuse \\
5 & Constant drooling; always wet \\
\hline
\end{tabular}

